\title{
RESEARCHPAPER
}

\section{Genetic analysis of Sesamum indicum L. germplasm using RAPD markers}

\author{
K. HANUMANTHA RAO ${ }^{1}$, RAMESH CHOUDHARY ${ }^{1}$ AND BHANWAR LAL JAT ${ }^{2}$ \\ ${ }^{1}$ Department of Agriculture, Bhagwant University, AJMER (RAJASTHAN) INDIA \\ ${ }^{2}$ Department of Agricultural Biotechnology, Bhagwant University, AJMER (RAJASTHAN) INDIA \\ Email : hanumantharao.agri@gmail.com
}

Article Info : Received : 25.05.2017; Revised : 17.08.2017; Accepted : 15.09.2017

Genetic diversity among 14 sesame (Sesamum indicum L.) accessions was examined at DNA level by means of random amplified polymorphic DNA (RAPD) analysis. Twenty primers used to produce a total of 201 RAPD fragments, of which 120 (59.70\%) were polymorphic. Each primer generated 4 to 15 amplified fragments with an average of 10.05 bands per primer. Based on pair-wise comparisons of RAPD amplification products, simple match similarity co-efficients were computed to assess the associations among the accessions. Pair-wise similarity indices varied from 0.63 to 0.91 . A UPGMA cluster analysis based on these genetic similarities located most of the accessions far apart from one another, showing a high level of polymorphism. Genetically, all the genotypes were classified into four major clusters. A single accession (Kayamkulam) was relatively distinct from rest of the accessions and created independent cluster. In conclusion, even with the use of a limited set of primers, RAPD technique revealed a high level of genetic variation among sesame accessions collected from diverse ecologies of India. This high level of genetic diversity among the genotypes suggested that RAPD technique is valuable for sesame systematic and can be helpful for the upholding of germplasm banks and the competent choice of parents in breeding programmes.

Key words : RAPD, DNA, Genetic analysis, Germplasm, Sesame

How to cite this paper: Rao, K. Hanumantha, Choudhary, Ramesh and Jat, Bhanwar Lal (2017). Genetic analysis of Sesamum indicum L. germplasm using RAPD markers. Asian J. Bio. Sci., 12 (2) : 194-201.DOI : 10.15740/HAS/AJBS/12.2/194-201. 